\title{
CrimRxiv
}

\section{Review 1 of "Exploring Employer Perceptions of Hiring Ex-Offenders"}

Chad Posick

Published on: Jan 12, 2022

DOI: 10.21428/cb6ab371.65027b7b

License: Creative Commons Attribution 4.0 International License (CC-BY 4.0). 
Vote: Publish pending Minor Changes

[Please explain your vote. If you voted to publish pending minor changes, specify each change, why it is needed, and, possibly, how it should/could be done.]

The manuscript is very well written and logically organized. It really was a pleasure to read. The topic of successful integration through employment opportunities for returning citizens is important and will be of interest to readers. The study methods were adequately covered and will be useful for both qualitative and quantitative researchers. I have one small comment. Since the authors are very knowledgeable about this area of study, I would have wanted a sentence or two at the end of the limitations section highlighting paths that future researchers can take to address the current study's limitations. What would such a project "look" like? 